\title{
Health Service Access Among Homeless Veterans: Health Access Challenges Faced by Homeless African American Veterans
}

\author{
Baylee Crone $^{1}$ (D) $\cdot$ Stephen Metraux ${ }^{2} \cdot$ Tracy Sbrocco $^{3}$
}

Received: 22 March 2021 / Revised: 21 July 2021 / Accepted: 22 July 2021 / Published online: 16 August 2021

(C) This is a U.S. government work and not under copyright protection in the U.S.; foreign copyright protection may apply 2021

\begin{abstract}
Veteran homelessness is a public health crisis, especially among the disproportionate number of minority veterans in the homeless veteran population. African American homeless veterans in particular face unique challenges accessing appropriate health care services to meet their medical needs. Their needs are often underrepresented in the literature on veteran homelessness. Drawing together over 80 studies and government reports from the last two decades, this review provides a timely synopsis of homeless veterans' health care access, with a particular focus on the barriers faced by African American veterans. This review employs Penchansky and Thomas' Access Model to frame health access barriers faced by homeless veterans, dialing in on what is known about the experience of African American veterans, within the five dimensions of access: Availability, Accessibility, Accommodation, Affordability, and Acceptability. Actionable guidance and targeted interventions to address health access barriers for all veterans are delineated with a focus on the need to gather further data for African American homeless veterans and to consider tailoring interventions for this important and underserved group.
\end{abstract}

Keywords Homeless $\cdot$ Veteran $\cdot$ Health service $\cdot$ Health access $\cdot$ Health disparities $\cdot$ Health model

\section{Introduction: Homeless Veterans and Unmet Medical Needs}

Although ending homelessness among veterans has been a national policy goal for over 20 years, thousands of veterans still call our nation's streets home every night [1]. A recent annual survey on homelessness found that 37,878 veterans were homeless on a single night and over 118,000 veterans accessed emergency shelter or short-term housing over the course of one year $[1,2]$. These annual surveys also found that, since 2009 , veterans were not only disproportionately represented among the overall homeless population but also that African American veterans in particular were overrepresented among veterans experiencing homelessness. Even more disturbing, between 2018 and 2019, while overall

Baylee Crone

baylee.crone@usuhs.edu

1 Uniformed Service University of the Health Sciences, Bethesda, MD, USA

2 University of Delaware, Wilmington, DE, USA

3 Uniformed Service University of the Health Sciences, Bethesda, MD, USA veteran homelessness numbers (including among White veterans) declined, the number of African American veterans experiencing homelessness did not change significantly [3]. ${ }^{1}$

Beginning in the early 1990s, research studies found that African American veterans were overrepresented among the homeless veteran population. Homeless African American veterans are often overrepresented in study samples compared to studies on the general veteran population, especially in studies conducted in nonrural areas [4-6]. African American veterans were noted to be disproportionately represented among the homeless veteran population when compared to the overall veteran population in Rosenheck and Fontana's landmark 1994 study on veteran homelessness [7]. This study also noted that veterans who identify as Black were more likely to experience prolonged or chronic homelessness following an initial homelessness episode.

Subsequent studies confirmed not only that African American veterans are overrepresented in study samples and in the homeless veteran population but also that race is a risk factor for homelessness. In fact, being African American was

\footnotetext{
${ }^{1}$ For a thorough examination of racial and ethnic disparities as they relate to homelessness, please review Fusaro VA, Levy HG, Shaefer HL. Racial and ethnic disparities in the lifetime prevalence of homelessness in the United States. Demography. 2018;55(6):2119-2128. doi:10.1007/s13524-018-07170 .
} 
associated with a 1.5 times increased risk of homelessness among U.S. Department of Veterans Affairs' (VA) Veteran's Health Administration (VHA) service users. Compared to being White, being African American increased the odds of homelessness almost four times in a recent study of VA mental health service users $[8,9]$.

In general, homelessness taxes veterans' health. Veterans experiencing homelessness are more likely to experience chronic stress and to be exposed to diseases and toxins from their environment [10-12]. Chronic, untreated medical conditions are common among homeless veterans and often include diabetes, cardiovascular disease, hepatitis, respiratory conditions, arthritis, and hypertension [13-17]. These untreated medical conditions significantly decrease quality of life and contribute to early mortality for up to 90 percent of veterans experiencing homelessness [12, 18-20]. Health outcomes specifically for minority veterans experiencing homelessness are understudied. $^{2}$

Some research shows, however, that systemic and cultural barriers prevent many homeless veterans - including African American veterans - from adequately using the right health services to match their medical needs [21]. From overreliance on emergency medical care to underutilization of preventative care, this pattern of disconnect between medical need and appropriate treatment is well documented within the VA's VHA system [22]. Fortunately, this disconnect can be addressed through improvements in fit between health service users (homeless veterans) and health service providers (to include the VA). For veterans experiencing homelessness, improved fit can lead to increased access and better health outcomes.

\section{Increased Access}

Increased access to health services benefits both veterans and the health care systems that serve them. It holds some of the keys to improve veterans' health and facilitate more efficient health care delivery [23]. Improving health care access is a notoriously complicated process [12]. Health service access models can help identify specific points of intervention to narrow gaps in care [24]. These conceptual models also provide a useful template for conceptualizing and categorizing population-specific deficits in care [25].

Until very recently, most health service conceptual models have left out populations experiencing homelessness, focusing only on the needs of the general (i.e., healthy and housed) population. Additionally, most conceptual models of health service are used to predict general patient satisfaction or

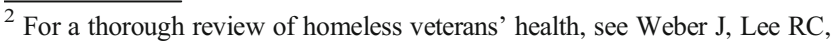
Martsolf D. Understanding the health of veterans who are homeless: a review of the literature. Public Health Nurs. 2017;34(5):505-511. doi:10.1111/ phn. 12338 .
}

emergency resource utilization, not to account for the unique factors impacting individuals experiencing homelessness [26]. This approach misses the important interactions between the health service system and any classically underserved subpopulations_-including homeless minority veterans [27].

Fortunately, the recent focus on meeting the health needs of historically underserved populations has reshaped our understanding of health care disparities [28]. In response, some conceptual models of health service have been revised to better capture the experiences of people who are homeless. ${ }^{3}$ The resulting models - such as the Gelberg-Andersen Behavioral Model for Vulnerable Populations - include barriers consistent with homelessness - including psychological distress and stress, mental health issues, poverty, and competing demands for time [26, 29-36].

No health service access conceptual model has specifically focused on homeless veterans and the health care services they use $[35,36]$. Although not specifically developed for use with homeless veterans, Penchansky and Thomas' Access Model (Access Model) may provide an ideal framework for understanding the fit between homeless veterans and health service systems and allow for the examination of factors that may disproportionately impact African American veterans. From their 1981 paper "The Concept of Access," the authors defined access as follows:

"[Access is] the opportunity or ease with which consumers or communities are able to use appropriate services in proportion to their needs... [It includes] the interface between potential users and healthcare resources, and would be influenced by characteristics of those who supply as well as those who utilize the services" [37].

The Access Model is unique in that it specifically addresses the fit between individuals and systems. By focusing on the fit between the two parties, it avoids the common pitfall of many health service access models - blaming access gaps on the individual or the system [35, 38].

The Access Model consists of five dimensions that define this fit between the individual and the health care system [37]. The dimensions include (1) Availability, (2) Accessibility, (3) Accommodation, (4) Affordability, and (5) Acceptability [39]. These dimensions are points of interaction between individuals and the health service system that either facilitate or stymie access to health services [40]. See Table 1 for definitions of these dimensions.

\footnotetext{
${ }^{3}$ See the comprehensive review of the Gelberg-Andersen Behavioral Model in Gelberg, Andersen, and Leake [2000] and the updated Gelberg-Andersen Behavioral Model for Vulnerable Populations in Gelberg et al. [2000], Gelberg, Browner, Lejano, and Arangua [2004], and Stein et al. [2007].
} 
Table 1 Dimensions of Access and Descriptions

\begin{tabular}{ll}
\hline Dimension name & Dimension description \\
\hline $\begin{array}{l}\text { (1) Availability } \\
\text { (2) Accessibility }\end{array}$ & $\begin{array}{l}\text { The extent to which the volume and type of services match consumer needs. } \\
\text { The fit between the location of services and the location of clients. } \\
\text { (3) Accommodation } \\
\text { The fit between how services are organized and the patient's ability to accept } \\
\text { thisture }\end{array}$ \\
(4) Affordability & $\begin{array}{r}\text { The price of care - after insurance - relative to the patient's available income } \\
\text { and the provider and patient mutual attitudes and perceptions. }\end{array}$ \\
(5) Acceptability & The proption of worth relative to cost.
\end{tabular}

While generally distinct concepts, these dimensions have some functional overlap when the model is applied to a specific population, such as African American homeless veterans. This paper aims to explore what is known about the health service access barriers among veterans who are homeless and to dial in on what is known for African American homeless veterans in particular. Second, we aim to discover what is known about tools/interventions to address the barriers faced by these veterans. The goal of this literature review is to integrate previous work in order to provide actionable policy and program suggestions to policy makers and advocates charged with filling gaps in health service access for this underserved population. Where little is known about African American veterans experiencing homelessness, we explore what is available, provide what was identified for the general homeless veteran population, and call for further research in key areas in order to obtain further information that will enable the development of tailored programs for African American veterans.

\section{Methods}

This narrative review assessed trends and patterns in health access among homeless veterans, and in particular among African American homeless veterans. Articles were reviewed for findings related to each of the five access dimensions: (1) Availability, (2) Accessibility, (3) Accommodation, (4) Affordability, and (5) Acceptability. This review attempted to make a unique contribution by drawing together findings on health access for veterans and examining the available data on African American veterans who are homeless within this context.

Studies were identified using an iterative search process. The initial search was conducted in PsycINFO using the following search terms and phrases: ("homeless veteran" AND "health access") OR ("homeless" AND "veteran" AND "health"). The initial PsycINFO search was limited to English language articles published between January 1980 and December 2018.

Based on the limited results obtained from the PsycINFO search, the authors chose to expand the search by using the same terms for homeless veterans and health access to search in PubMed, Google Scholar, and PowerSearch, a search and discovery platform comprised of the Uniformed Services University of the Health Sciences (USUHS) library's collections. Additionally, the authors completed a hand search of references from the included articles to identify additional relevant articles and searched the gray literature for applicable government reports and documents. Following the review of the initial PsycINFO search results retrieved in December 2018, the PsycINFO search was updated in May 2021 to capture relevant publications released through the end of 2019. At this time, the search was also run with the expanded list of databases and online searches to retrieve additional relevant papers from these other sources.

Studies were included in this narrative review if they included a sample of concurrent or recently homeless veterans and included study variables related to the interaction of veterans and the health system and if they were either qualitative or quantitative studies (or review of these studies). Where research specific to veterans experiencing homelessness was dated, limited, or absent completely, limitations are noted and supplemental topic-relevant general homeless population or nonhomeless population research was included as a point of reference for the reader, with the need for additional research on these specific topics noted throughout.

\section{Results}

This review presents findings across the identified studies and reports for the 5 dimensions of the Access Model. Each dimension includes a series of barriers as well as targeted tools and interventions to address the specific barriers. Seventy-five articles and six government reports were identified using this strategy. Of these, 50 articles focused on one domain and 31 articles included information on more than one domain. Twenty-four of these articles offered information on addressing access barriers across all dimensions. See Table 2 for a detailed overview of the articles on barriers by dimension and Table 3 for an overview of articles on tools and interventions by dimension. For both tables, the 5 dimensions are listed across the top with the articles grouped based on whether they 
Table 2 Articles Including Barriers by Dimensions

\begin{tabular}{|c|c|c|c|c|c|c|c|}
\hline & \multicolumn{2}{|l|}{ Article information } & \multicolumn{5}{|c|}{ Five dimensions of access } \\
\hline & Article author & $\begin{array}{l}\text { Article } \\
\text { year }\end{array}$ & $\begin{array}{l}\text { (1) } \\
\text { Availability }\end{array}$ & $\begin{array}{l}\text { (2) } \\
\text { Accessibility }\end{array}$ & $\begin{array}{l}\text { (3) } \\
\text { Accommodation }\end{array}$ & $\begin{array}{l}\text { (4) } \\
\text { Affordability }\end{array}$ & $\begin{array}{l}\text { (5) } \\
\text { Acceptability }\end{array}$ \\
\hline \multirow{4}{*}{$\begin{array}{l}\text { More than one } \\
\text { dimension }\end{array}$} & Armstrong et al. & 2006 & $\mathrm{X}$ & & & & $X$ \\
\hline & GAO & 2000 & $\mathrm{X}$ & $\mathrm{X}$ & & & \\
\hline & Kushel et al. & 2001 & & & $\mathrm{X}$ & & $\mathrm{X}$ \\
\hline & O’Toole et al. & 2013 & $X$ & & & & $\mathrm{X}$ \\
\hline \multirow[t]{42}{*}{ One dimension } & Baggett et al. & 2010 & & & & $\mathrm{X}$ & \\
\hline & Blue-Howells & 2019 & & & & & $\mathrm{X}$ \\
\hline & Cheney et al. & 2018 & $\mathrm{X}$ & & & & \\
\hline & CRS & $2016 c$ & $\mathrm{X}$ & & & & \\
\hline & D'Amore et al. & 2001 & & $X$ & & & \\
\hline & Desai et al. & 2003 & & & & & $X$ \\
\hline & Doran et al. & 2014 & & & & & $X$ \\
\hline & Feigal et al. & 2014 & $\mathrm{X}$ & & & & \\
\hline & Fischer et al. & 1986 & & & & & $X$ \\
\hline & Fortney et al. & 1995 & & $\mathrm{X}$ & & & \\
\hline & Gabrielian et al. & 2014 & & & & & $X$ \\
\hline & Gabrielian et al. & 2017 & & & & & $\mathrm{X}$ \\
\hline & Gamache et al. & 2000 & $\mathrm{X}$ & & & & \\
\hline & Gelberg et al. & 1997 & & & & $X$ & \\
\hline & Gelberg et al. & 2000 & $\mathrm{X}$ & & & & \\
\hline & Gilmer et al. & 2009 & $\mathrm{X}$ & & & & \\
\hline & Gilmer et al. & 2020 & & & & & $\mathrm{X}$ \\
\hline & Gordon et al. & 2010 & & & & & $X$ \\
\hline & Gulcer et al. & 2003 & $\mathrm{X}$ & & & & \\
\hline & Gundlapali et al. & 2015 & & & $X$ & & \\
\hline & Harris et al. & 2018 & & $X$ & & & \\
\hline & Hamilton et al. & 2012 & & & & & $X$ \\
\hline & Henwood & 2013 & & $X$ & & & \\
\hline & Hill et al. & 2013 & & & & & $\mathrm{X}$ \\
\hline & Jones et al. & 2017 & & & & & $\mathrm{X}$ \\
\hline & Kinchen et al. & 1991 & & & $X$ & & \\
\hline & Kushel et al. & 2006 & & $\mathrm{X}$ & & & \\
\hline & Metraux et al. & 2017 & & $\mathrm{X}$ & & & \\
\hline & Montgomery et al. & 2017 & $X$ & & & & \\
\hline & O'Toole et al. & 2003 & $\mathrm{X}$ & & & & \\
\hline & O'Toole et al. & 2015 & & & & & $X$ \\
\hline & Padgett et al. & 1995 & $\mathrm{X}$ & & & & \\
\hline & Priester et al. & 2016 & & $X$ & & & \\
\hline & Rae \& Bees & 2015 & & & & & $X$ \\
\hline & $\begin{array}{l}\text { Rosenheck \& } \\
\text { Fontana }\end{array}$ & 1994 & & $X$ & & & \\
\hline & Semeah et al. & 2017 & & & & & $\mathrm{X}$ \\
\hline & Shulman et al. & 2018 & & & & $X$ & \\
\hline & Syed et al. & 2013 & & $\mathrm{X}$ & & & \\
\hline & Tsai et al. & 2017 & & $X$ & & & \\
\hline & Tsai et al. & 2018 & & & & $X$ & \\
\hline & Weber et al. & 2018 & & & $X$ & & \\
\hline & Wen et al. & 2007 & & & & & $X$ \\
\hline
\end{tabular}


Table 2 (continued)

\begin{tabular}{|c|c|c|c|c|c|c|}
\hline \multicolumn{2}{|c|}{ Article information } & \multicolumn{5}{|c|}{ Five dimensions of access } \\
\hline Article author & $\begin{array}{l}\text { Article } \\
\text { year }\end{array}$ & $\begin{array}{l}\text { (1) } \\
\text { Availability }\end{array}$ & $\begin{array}{l}\text { (2) } \\
\text { Accessibility }\end{array}$ & $\begin{array}{l}\text { (3) } \\
\text { Accommodation }\end{array}$ & $\begin{array}{l}\text { (4) } \\
\text { Affordability }\end{array}$ & $\begin{array}{l}\text { (5) } \\
\text { Acceptability }\end{array}$ \\
\hline Wenzel et al. & 1995 & $\mathrm{X}$ & & & & \\
\hline Zucchero et al. & 2016 & & & & $\mathrm{X}$ & \\
\hline Zur et al. & 2014 & & & & $\mathrm{X}$ & \\
\hline
\end{tabular}

addressed one or multiple dimensions. The dimensions addressed are indicated by an " $\mathrm{X}$ " in the corresponding box by dimension.

In the 81 studies and reports, 27 (33 percent) made no mention of race whatsoever. Fifty-two of the studies included race in the descriptions of the demographics of the study sample, while 22 of the studies included race as a control variable. While only two studies stated that they took race into consideration during recruitment, 22 studies presented findings and conclusions in their results or discussion specific to race.

Studies are summarized below by dimension, starting with the specific barriers impacting access to health care within each dimension. Next, intervention strategies that target these barriers are discussed by dimension. Although there is a paucity of data for African American veterans, for studies in this review that did include race as a primary variable of the study, relevant findings related to race or ethnic identity are noted within the discussions on access.

\section{Barriers to Access and Interventions/Tools by Dimension}

\section{Availability Dimension}

According to the Access Model, Availability is defined as the extent to which the volume and type of services match consumer needs. It generally includes the number of providers, the number of facilities, available technology, and the quantity of specialized programs and services. Availability issues can emerge due to perceptions of lack of Availability. Twentythree articles and reports included in this review addressed

Table 3 Articles Including Tools/Interventions by Dimensions

\begin{tabular}{|c|c|c|c|c|c|c|c|}
\hline & \multicolumn{2}{|l|}{ Article information } & \multicolumn{5}{|l|}{ Dimensions } \\
\hline & Article author & $\begin{array}{l}\text { Article } \\
\text { year }\end{array}$ & $\begin{array}{l}\text { (1) } \\
\text { Availability }\end{array}$ & $\begin{array}{l}\text { (2) } \\
\text { Accessibility }\end{array}$ & $\begin{array}{l}\text { (3) } \\
\text { Accommodation }\end{array}$ & $\begin{array}{l}\text { (4) } \\
\text { Affordability }\end{array}$ & $\begin{array}{l}\text { (5) } \\
\text { Acceptability }\end{array}$ \\
\hline \multirow{2}{*}{$\begin{array}{l}\text { More than one } \\
\text { dimension }\end{array}$} & CRS & 2018 & $X$ & $X$ & & & \\
\hline & Weissman et al. & 2005 & $\mathrm{X}$ & & & & $\mathrm{X}$ \\
\hline \multirow[t]{15}{*}{ One dimension } & Blue-Howells & 2019 & $\mathrm{X}$ & & & & \\
\hline & Chinchilla et al. & 2020 & & $\mathrm{X}$ & & & \\
\hline & Cretzmeyer et al. & 2014 & $\mathrm{X}$ & & & & \\
\hline & Corrigan et al. & 2015 & & & & & $X$ \\
\hline & Corrigan et al. & 2017 & & & & & $X$ \\
\hline & CRS & $2016 a$ & $X$ & & & & \\
\hline & CRS & $2016 b$ & $X$ & & & & \\
\hline & Harris et al. & 2018 & & & & & $X$ \\
\hline & Molinari et al. & 2013 & & & & & $\mathrm{X}$ \\
\hline & Montgomery et al. & 2017 & & & & & $\mathrm{X}$ \\
\hline & Resnick et al. & 2016 & & $\mathrm{X}$ & & & \\
\hline & Suris et al. & 2017 & $\mathrm{X}$ & & & & \\
\hline & Tsai et al. & 2018 & $\mathrm{X}$ & & & & \\
\hline & $\begin{array}{l}\text { Van Voorhees } \\
\text { et al. }\end{array}$ & 2019 & & & & & $\mathrm{X}$ \\
\hline & $\begin{array}{l}\text { VHA Homeless } \\
\text { Programs }\end{array}$ & 2013 & & & $\mathrm{X}$ & & \\
\hline
\end{tabular}


the dimension of Availability. Fourteen articles identify Availability barriers, and nine provide some guidance on tools and interventions targeting Availability barriers. Of articles in this review under this dimension, 13 include race in their descriptions of sample demographics and five include race primarily as a control variable. Only three articles discussed race, with only one article identifying and discussing significant differences in outcomes by race.

One pervasive theme across articles is the expansiveness of the VA's VHA system. The VHA is the nation's largest integrated health care system: in addition to 172 VA Medical Centers (VAMCs), the VHA network includes over 1,000 community clinics across 23 Veteran Integrated Service Networks (VISNs) [41]. In addition to these VHA facilities, the VA provides outside network care services as needed through the Veterans Choice Program (VCP) and the Maintaining Systems and Strengthening Integrated Outside Networks Act of 2018 (Mission Act). These additions allow veterans to access outpatient, inpatient, and emergency care in the community [42]. This system provides health care services to over 6.7 million eligible veteran patients, representing a massive Availability asset unique to the veteran population. The VA is currently the largest federal investor in telemedicine, using mobile phones, video conferencing, and asynchronous communication to meet medical needs for remote patients [43].

Given the expansive reach of the VA health system to veterans overall, the assumption could be made that homeless veterans routinely access available VA health care and that the dimension of Availability is adequately fulfilled. However, research included in this review shows that available health insurance does not always translate into available health services. O'Toole and colleagues examined sources of usual care for homeless veterans in and around Pittsburgh and Philadelphia and found that (compared to homeless nonveterans) homeless veterans had significantly higher rates of insurance coverage, with a significant component of this difference attributable to VA coverage [44]. However, O'Toole and colleagues also found that while 65 percent of homeless veterans had health coverage, only 41 percent used that coverage to access health services. Studies in this review support the finding of an Availability barrier for those homeless veterans who have coverage and do not use it.

A homeless veteran may be eligible for health services at the VA but may fail to use his VA insurance coverage. This phenomenon is particularly acute among African American homeless veterans: in a 2003 study on the federal program Health Care for Homeless Veteran (HCHV), researchers found that while there was no difference in initial VA appointments, homeless veterans who identified as African American were less likely to receive follow-up care [45]. Reasons for these differences were not quantified by Desai and colleagues, and no subsequent study has explored this gap in access for
African American homeless veterans [45]. Distrust may be one factor in this Availability barrier: among the general population, distrust in the medical system is associated with worse health outcomes [46], and among veterans, lack of faith in the VA system is associated with decreased use of mental health services [47].

Additionally, health service eligibility does not necessarily translate into Availability of the right kinds of services that veterans experiencing homelessness need to meet their most pressing health needs. Over the last twenty years, research on homeless individuals in general has found that they are more likely to seek care through emergency rooms and not through primary or preventive care $[26,48,49]$. Older research on homeless veterans found a similar pattern. That is, they tend to use services that meet acute needs rather than long-term or preventive needs, leading to repeat visits and hospitalizations [50]. More recent studies on homeless veterans find that they still often utilize emergency services as the first access point for care $[16,51,52]$ with lower rates of outpatient service use [45]. Lack of discharge options means veterans who are homeless stay longer than necessary in hospitalization or emergency services [48, 49, 51]. Although four of these studies included race as a control variable, none addressed race variables in their findings or discussion.

Other veterans are not eligible for health care services within the VHA. For veterans with a short Active Duty service record or a discharge status below honorable, for example, VHA health care eligibility may be partially or fully restricted [53]. Recent research shows that homeless veterans have a disproportionate number of discharges below honorable [54]. For these and many other veterans, Availability is limited by eligibility. No studies included in this review specifically address the relationships between race and discharge status among homeless veterans.

VA-ineligible homeless veterans would instead need to seek medical care through employer-sponsored programs or limited community or state health service programs [44]. Fulfilling paperwork requirements for public assistance is considerably more difficult for individuals experiencing homelessness. Although this has not been examined with homeless veterans seeking public health services, it is likely that this general homeless population pattern persists among veterans experiencing homelessness [55].

Several tools and interventions can address Availability barriers for homeless veterans who are eligible for health care but do not use it and for veterans who are not eligible for health care (two major barriers identified in this review). Efforts to move VA services into the community-primarily through Community-Based Outpatient Clinics (CBOCs) and Community Resource and Referral Centers (CRRCs) - help meet homeless veterans where they are [56]. Local community-based programs and community leaders play a critical role in educating veterans about their eligibility for 
health services [57]. Mobile clinics also reach veterans who are not engaged with the VA system, including those with high homelessness chronicity [58]. These interventions and tools address Availability barriers by bringing services closer to the veterans who are eligible for health care but are not accessing it.

For homeless veterans facing Availability barriers because they are currently ineligible for VA health care, discharge upgrades and expansions in health care eligibility for veterans with an other than honorable discharge status could significantly increase eligibility to promote Availability $[59,60]$. These strategies address Availability barriers to improve health care access. Unfortunately, these strategies have yet to be evaluated for their effectiveness in reaching African American veterans experiencing or at risk of homelessness.

\section{Accessibility Dimension}

In the Access Model, Accessibility is defined as the fit between the location of services and the location of clients. Barriers could include transportation, geographic barriers, or distance between a service user and a service location. Thirteen articles and reports addressed the dimension of Accessibility. Eleven articles and reports identify Accessibility barriers. One article offered tools/interventions for addressing Accessibility issues, and a government report presents another tool to address Accessibility barriers although it was not studied specifically for this purpose. Six articles in the dimension included a discussion of race when reviewing the demographic profile of study participants, and three primarily included race as a control variable. While one article discussed the general impact of race on homelessness risk, it failed to take the step of connecting race to one of its variables of study - social isolation. Two other articles in this dimension discussed race as a primary focus of the study, with one presenting significant results.

Although transportation can be an Accessibility barrier for all populations, it is particularly impactful for veterans experiencing homelessness [55, 61-63]. Among the general homeless population, limited disposable income means fewer funds available for public transportation, and homeless individuals are less likely to own working vehicles [33]. Among homeless veterans - especially those in rural areas - this transportation gap exacerbates chronic disease burden in already underserved communities and reinforces activities that lead to poor health, such as poor diet or limited exercise [64].

The social isolation commonly experienced by homeless veterans may also exacerbate Accessibility issues. Social isolation is prominent among homeless veterans: two studies found that they report increased social distance and higher levels of social isolation $[8,13]$. Early research on veteran homelessness risk factors found that not having social support during the first year after discharge from the military and being unmarried were associated with subsequent homelessness [7]. More recent research on Post-9/11 veterans found that relationship dissolution was closely related to homelessness risk [65]. According to two studies, not only do veterans experiencing homelessness have less support physically going to and from medical appointments, but social isolation can also limit social pressure to pursue needed medical care, knowledge of available services, or even a desire to pursue care more broadly [14, 55]. Chinchilla and colleagues (2019) found no significant differences between African American and White veterans on measures of community adjustment [66]. Beyond Chinchilla and colleagues' study, social isolation among African American homeless veterans was not a focus area in these studies.

Some interventions hold potential for addressing the Accessibility barriers of transportation and social isolation. However, research is limited on their effectiveness at directly targeting Accessibility issues for homeless veterans in general and for homeless African American veterans in particular. For example, the Veteran's Choice Program (VCP) was developed specifically to increase health access for veterans who were a considerable geographic distance from a VAMC or who needed specialty services not otherwise available in a defined waiting period [42]. This program could, in theory, address some transportation barriers faced by homeless veterans; however, no research was found on the effectiveness of this expansion in managing health care for homeless veterans or in reaching vulnerable African American veterans. Decreased social isolation can be accomplished through expansion of housing programs that reinforce safety and community—such as Project-Based HUD-VASH [66]—a program that has housed a disproportionately high percentage of homeless African American veterans in recent years.

\section{Accommodation Dimension}

Accommodation is defined as the fit between how services are organized and the patient's ability to accept this structure. This dimension also includes the patient's perception of the reasonableness of the organization of services. Four articles identified Accommodation barriers, and one report included in this review provided interventions addressing Accommodation barriers. One article in this dimension addressed medication adherence and race, and two others mentioned race in their review of demographics.

This review revealed one major Accommodation barrier: medication regimen planning. Among the general population, Kinchen and colleagues (1997) found that over 30 percent of homeless respondents reported that they could not comply with a medication regimen [67]. Individuals experiencing homelessness may struggle to adhere to treatment due to the difficulty of managing medication while homeless, even if the medication is available and otherwise accessible [68]. Several 
compounding factors can lead to medication nonadherence, including limited provider follow-up, lack of refrigeration resources, or lack of secure settings for medications [67].

Recent research on medication adherence for homeless veterans is limited. However, one study found that homeless veterans who are otherwise engaged with their medication regimen may still be unable to complete it due to factors dependent on their homelessness status (e.g., limited food to take with medications that must be taken with meals and lack of refrigeration) [69]. Another study of homeless veterans with hepatitis $\mathrm{C}$ found that receipt and use of appropriate medications were significantly lower among homeless veterans when compared to housed veterans [70]. In this study, African American veterans in general were more likely to begin treatment. However, this difference was no longer statistically significant when limited to those veterans experiencing homelessness. As noted by Gundlapalli and colleagues (2015), this lack of treatment initiation could be due to the burden that treatment places on individual veterans seeking care. Providers may fail to initiate treatment with homeless veterans because of this anticipated burden. In this case, initiation of treatment involving needed medications may have been stymied by the veterans' and the providers' determination that the structure of services was unreasonable.

Interventions to provide medication assistance can address this specific Accommodation barrier. When the veteran does not have secure facilities for medications, the provider can work with a local community-service agency, such as a VA Grant and Per Diem (GPD) provider or Medicaid or statefunded managed care provider, which provides medication management, medication monitoring, or individual storage [71].

\section{Affordability Dimension}

In the general model, the Affordability dimension includes the price of care - after insurance - relative to the patient's available income and the patient's perception of worth relative to cost. Affordability barriers for the general population are centered on cost (e.g., expensive procedures or medications outside of the patient's income or the patient's unwillingness to pay for preventive care or longer-term treatment). For homeless veterans, however, health service Affordability is also about opportunity costs. As noted in Table 2, five articles and one government report included in this review identified Affordability barriers. No articles quantified interventions/ tools for addressing Affordability barriers. Only two articles in this dimension included race in their demographic discussion, and none of the articles in this section specifically addressed race-specific Affordability issues. In fact, half of the articles in this dimension made no mention of race at all.

As noted above, the VHA system is generally a no- or lowcost option for those homeless veterans who are enrolled, eligible, aware, and able to travel to health services. Homeless veterans are unique in their ability to access multiple health care resources, including other mainstream sources such as private insurance, Medicaid, and Medicare [72]. In states that voluntarily chose to expand their Medicaid programs after the passage of the Affordable Care Act, homeless individuals including veterans had even greater access to lowor no-cost health services [73]. As a result, the Affordability domain focuses less on financial cost and more on opportunity cost when applied to homeless veterans.

Competing priorities function as Affordability barriers to health service access when veterans must weigh the cost of accessing health care versus addressing other needs [32]. Veterans experiencing homelessness must secure priorities that may be higher on their list of needs (e.g., shelter for the night or legal assistance) [60]. For example, a veteran may want to attend a medical appointment, but doing so would require taking time off work and losing out on needed income. For some homeless individuals, finding daily resources like food and shelter takes precedence over seeking medical care $[23,74]$. Homeless veterans who otherwise have access to no-cost or low-cost health services may still not be able to afford care if the trade-offs prove too costly. Addressing Affordability barriers requires managing competing care needs, yet no published studies identified in this review explicitly explored competing care needs among homeless veterans.

\section{Acceptability Dimension}

The dimension of Acceptability includes the provider and patient mutual attitudes and perceptions. Acceptability focuses on agreement between the provider and the patient. No articles in this search focused specifically on the agreement between homeless veterans and the providers who serve them; however, four articles focused on Acceptability in the general homeless population, and 21 articles and reports indirectly addressed barriers and interventions targeting Acceptability. Fourteen articles in this dimension included race in their description of demographics, and six used race primarily as a control variable. Three studies included in this dimension discussed findings directly related to race. Another study included race in their methods but failed to discuss any findings related to race.

Homeless veterans' perception of their providers - a major component of Acceptability - centers on trust, stigma, and collaboration. In one early qualitative study by Wen and colleagues (2007), homeless patients characterized an experience of "unwelcomeness" defined by rude treatment, rushed appointments, and discrimination based on housing status. One participant reported that he perceived his African American race to be a factor in his perception of unwelcomeness in health care encounters [75]. In a more recent study, homeless 
veterans reported more negative primary care experiences than housed veterans across seven of eight domains of care. These negative experiences applied not only in interpersonal domains but also in veteran perception of the thoroughness of treatment and their role in medication decision-making [76]. In some cases, homeless veterans reported delaying entry into primary care services due to a lack of trust in providers and perceived stigma as a result of their homelessness status [77]. For homeless female veterans, the perception of lack of suitable services may compound the difficulty of accessing care because of their homelessness and their gender [78].

No study identified in this review focused on clinician perception of homeless veterans specifically. One general population study using a subset of questions from the Health Professional Attitudes Toward the Homeless Inventory (HPATHI) found that emergency department clinicians selfreported neutral to positive feelings toward homeless patients [79]; ${ }^{4}$ the authors did not relate this perception to the actual provision of care in the study, but suggested strategies for engaging emergency room clinicians in homelessness initiatives to generate a closer working relationship. Other studies have documented the perception of clinician bias as a factor in suboptimal care and decreased intent to engage in services among the general homeless population $[80,81]$.

Other studies on homeless veteran care providers give some insight into their relationship with the veterans they serve. A review of provider and patient needs found that case managers' core objectives are generally based on the mission of their agency, potentially creating conflict with the goals of the veteran [59]. Another study of case managers found that 88 percent reported experiencing some form of violence or aggression during housing visits. These care providers may not feel safe visiting the locations where homeless veterans reside, especially when these locations are in neighborhoods with histories of violence [82]. It is possible that provider fear and safety concerns could limit treatment access, but more study is needed.

Diversion into substance use treatment programs may represent another Acceptability disconnect between veterans and providers. In several studies, veterans who were homeless reported difficulty accessing health services that may have actually been available in their care facility, especially if the veteran had complicated medical issues [4, 45, 46, 68, 83-85]. For example, one study of homeless veterans seeking primary care services found that these veterans were more likely to be quickly diagnosed with a mental health condition and less likely to be diagnosed with a chronic disease condition than veterans in a housed comparison group [16]. Another found that a diagnosis of substance abuse - common in the homeless

\footnotetext{
${ }^{4}$ Buck, D.S., Monteiro, F., Kneuper, S. et al. Design and validation of the Health Professionals' Attitudes Toward the Homeless Inventory (HPATHI). BMC Med Educ 5, 2 (2005). https://doi.org/10.1186/1472-6920-5-2.
}

veteran population - was associated with a decreased likelihood of receiving general health care services, even when the veteran was contacted specifically for medical outreach. Even veterans in VA Health Care for Homeless Veterans sites with more robust mental health resources had low rates of medical follow-up [45]. This could mean, for example, that a homeless veteran could be first directed to a substance use or mental health treatment program before she is directed to care for her medical issue.

Peer navigators are one intervention to address Acceptability barriers by improving veteran perception of and trust in health systems and providers. Although the exact job tasks of peer navigators vary by location, in general, VA peer navigators are veterans who have experience with homelessness and/or with navigating the VA health care system and can therefore serve as resources for their peers. These peer support resources have shown promise in supporting African American homeless veterans [86]: one study in particular found that homeless African Americans perceived peer navigators to be a useful source of practical logistical information and a resource for troubleshooting creative ways to engage meaningfully in the health system [87]. Another study on peer navigators found that ninety percent of homeless veterans accessing peer navigator services identified as members of minority groups; when peer navigators share demographic characteristics and identities with those they serve, veterans may feel more trusting and be more amenable to accessing care [56]. Peer navigators' shared experiences allow for interpersonal support and empathy, leading to positive health and housing outcomes $[14,52,56,88-90]$.

\section{Interventions Working Across the Five Dimensions}

Each of the interventions discussed above targets dimensionspecific barriers to health access but likely also has some spillover impact on health access barriers in other dimensions. For example, peer navigators primarily target Acceptability barriers, but they can help veterans manage competing care needs (Affordability) or help veterans identify other services for which they are eligible (Availability). Other interventions impact health access barriers across dimensions; 24 articles covered these cross-dimension tools. Because they cannot be easily categorized in one dimension, they are described separately here. Of these articles, 12 included race in the demographic profile of study participants, and five used race primarily as a control variable. An additional two articles in this section provided significant results and discussions related to race.

\section{Affordable Housing}

Housing stability not only is a major social determinant of health but also continues to be a critical method for supporting improved quality of life, pursuing needed health services, and 
meeting health needs $[55,65,91-93]$. Supportive housing is associated with decreased hospitalizations, length of stay in hospital, and incarceration [94]. These positive outcomes of supportive housing benefit homeless African American veterans [21].

Affordable housing is an intervention working across several dimensions of access: a secure home can improve medication adherence (Accommodation); housing stability could decrease bias from care providers (Acceptability); a housed setting could provide the community that promotes social support systems (Affordability). Housing stability allows veterans to devote financial resources to other basic or preventive needs (e.g., transportation to medical appointments, Availability and Accessibility) [95].

\section{Enrollment in Primary Care}

For many veterans experiencing homelessness, primary care enrollment can be a gateway to other health services [96, 97]. In several studies, primary care enrollment is associated with decreased emergency department use and better use of general health services, a step toward addressing Availability barriers. It is also associated with increased medication regimen adherence (Accommodation) among homeless veterans $[16,98]$. Receipt of primary care services is also protective against future eviction [99]. Promoting primary care enrollment could address the uneven utilization of services and help promote treatment adherence.

\section{Colocated Services}

Colocation of services involves placing homeless services and medical services in the same physical space. In one study, colocation of homeless-specific services with the emergency department was favored by patients and clinicians while in another the colocation of on-site nursing care resources decreased emergency department visits and improved medication adherence and outcomes [100]. Colocation's effectiveness is magnified by program improvement initiatives aimed at achieving concrete benchmarks and integrating services. Several of these initiatives have shown promising preliminary success when applied to VA programs serving homeless veterans, such as the Getting To Outcomes (GTO) program or the Maintaining Independence and Sobriety through Systems Integration, Outreach, and Networking (MISSION) intervention [101-105].

The VA's Homeless Patient Aligned Care Teams (HPACTs) in particular have led to dramatic decreases in emergency room visits and hospitalizations [106]. H-PACTs work across several dimensions. By colocating medical and homeless program staff members, H-PACTs utilized at some VAMCs offer a valuable template for increasing health service Availability at all VA sites (Availability) [70]. Integrating a mental health pharmacy resource into an H-PACT location can improve medication adherence through education and more rapid responses to patient concerns (Accommodation) [107]. H-PACTs can transport veterans to at least their first medical appointment (Acceptability). In fact, in a study by O'Toole and colleagues, veterans who were transported to a medical interview in an H-PACT system were more likely to then engage in a subsequent first medical appointment [106]. Although this review did not identify any specific benefits to homeless African American veterans in regard to colocation of services, it is likely that further expansion of H-PACTs across VAMCs will bridge gaps in care across veteran groups. This particular area of care is deserving of future investment and study.

\section{Expanded Use of Remote and Virtual Resources}

Remote and virtual platforms and tools resolve several barriers to access by shrinking the distance, response time, and (when employed effectively) formality of traditional in-person medical appointments. In one study, 89 percent of veterans had a mobile phone and health was the second most common reason for using their phones [108]. For recently housed veterans, in-home health information technologies - including the Care Coordination Home Telehealth (CCHT) programhold promise for closing some of the Availability gaps for veterans managing chronic illnesses [109].

\section{Discussion}

One of the most striking outcomes when looking across studies included in this review is the paucity of data related to health access among African American homeless veterans. Specifically, of the over six dozen articles included in this review, only 21 included race as one of the primary variables in the study. Race was included in 52 studies to establish a demographic profile of the sample, but without additional discussion thereafter. Homelessness research is not alone in this exclusion process. One recent review found that only 1.4 percent of biomedical systematic reviews included race or ethnicity in subgroup effect analyses (116).

How to best integrate race variables in researchespecially medical research — can be polarizing. While many progressive researchers are in favor of advancing beyond a pure essentialist approach to race's inclusion in research, the process by which race can be methodologically constructed or disaggregated is still undecided. For example, some scholars advocate for treating race more as a composite measure and less as an immutable characteristic [110]. Given how sparingly race is addressed in the homeless veteran literature, we suggest that race be used as an incremental variable where appropriate while more comprehensive sociological and 
biological variables are developed and defined [111]. We also suggest that researchers make every effort to adopt precise terminology based on fairness and equity (112). ${ }^{5}$ Knowing that health outcomes are worse for African American homeless veterans, we believe that additional attention should be given to this specific group of veterans in future health literature.

Several steps can be taken to begin addressing this omission. Experts and leaders should reexamine foundational research that included race using a contemporary conceptual and methodological lens. Wherever possible, this group of evaluative experts and leaders should include representatives from the population of study. In this case, that would mean including African American veterans who have experience with or are experiencing homelessness. This evaluation process would involve looking not only at the analyses used in the foundational studies but also at the data gathering process itself. For example, we would want to know how information on race was obtained, and if the findings map onto our current understanding of race and health disparities.

While important for establishing the generalizability of the results, including race in the discussion of demographics is conceptually and statistically insufficient. We encourage researchers to consider during the study design phase if race (or another comparable measure) is linked in a meaningful way-either through conceptual modeling or previous study - to the variables of interest and to adjust study design accordingly. For example, a future study on COVID-19 vaccine uptake among homeless veterans in the shelter system should not only gather race data to establish the study's generalizability but also critically examine whether homeless African American veterans faced any additional or unique barriers to access.

The fact that African American veterans are disproportionately overrepresented among the homeless veteran population is established by over a decade of comprehensive population reports, as noted above. This long-standing reality has not adequately propelled research that explains the disparity, let alone evaluated the role of health care and health service access in homelessness. Addressing the long-term healthrelated factors that exacerbate or are exacerbated by homelessness requires more study of the specific barriers African American veterans face when trying to access health care. While several fields play a role in addressing the disproportionate lack of access among homeless African American

\footnotetext{
$\overline{5}$ For a thorough discussion of the benefits and drawbacks of including race in research, please review the following articles: Sen, M. \& Wasow, O. (2016). Race as a bundle of sticks: designs that estimate effects of seemingly immutable characteristics Annual Review of Political Science, 19, 499-522; Ioannidis J.P., Powe, N.R., Yancy, C. (2021). Recalibrating the use of race in medical research. JAMA, 325(7), 623-624. doi:10.1001/jama.2021.0003; and Flanagin A, Frey T, Christiansen SL, Bauchner H. (2021). The reporting of race and ethnicity in medical and science journals: comments Invited. JAMA, 325(11), 1049-1052. doi:10.1001/jama.2021.2104.
}

veterans, the health care system including but also beyond the VA system is uniquely positioned to meet the needs of these veterans using some of the strategies noted below.

Continuing to look across the studies included in this review, the authors were able to identify tools/interventions and barriers that either increased or decreased health access, respectively. While certain tools/interventions had the largest impact in one dimension, several others crossed dimensions. Fig. 1 provides an overview of the barriers and tools/ interventions identified in this review across Access Model dimensions as they relate to health access.

Four of the identified high-impact tools - affordable housing, primary care enrollment, colocation, and virtual resources-work across dimensions and can be expanded through advocacy and program coordination. First, to increase affordable housing stock, advocates can support ongoing housing development initiatives such as Project-Based HUD-VASH or GPD's Transition In Place. Local advocates can work with Public Housing Authorities to increase their project-based allocations of housing vouchers in support of development projects. Continued case management is essential at these project-based sites, so local advocates and VA partners should ensure sufficient HUD-VASH and other case management services to meet the needs of veterans as they transition into independent housing.

Second, to enroll homeless veterans in primary care services, experts suggest tailoring outreach services so they are accessible to the veteran and targeted in their focus [44, 94, $112,113]$. This process can go beyond simply orienting veterans to the clinic by providing brief interventions to provide immediate relief [25]. In fact, O'Toole and colleagues predicted a dose-effect in this process - if one outreach event can increase engagement in primary care, a sustained effort will likely have a magnified effect [98].

To facilitate colocation, VAMCs can support local community providers by providing office, meeting, and training space within CRRCs or other community-based clinics. Where feasible, H-PACTs should be expanded to ensure close physical and mission proximity for major partners serving veterans experiencing homelessness. Finally, VA can expand and continue the use of virtual appointments even after the acute COVID-19 era. Providers should be conscious of how veterans connect virtually by putting in place social media policies and relying on phone calls over text messaging or email.

Within the individual dimensions, barriers and interventions are often closely linked. The Availability studies, for example, show several barriers to access that are closely linked to the tools in this dimension. We cannot assume that all homeless veterans have full health service access simply because the VHA system exists. Even veterans who are eligible for VA care may not find these resources available to them. While homeless veterans may be able to access VHA 


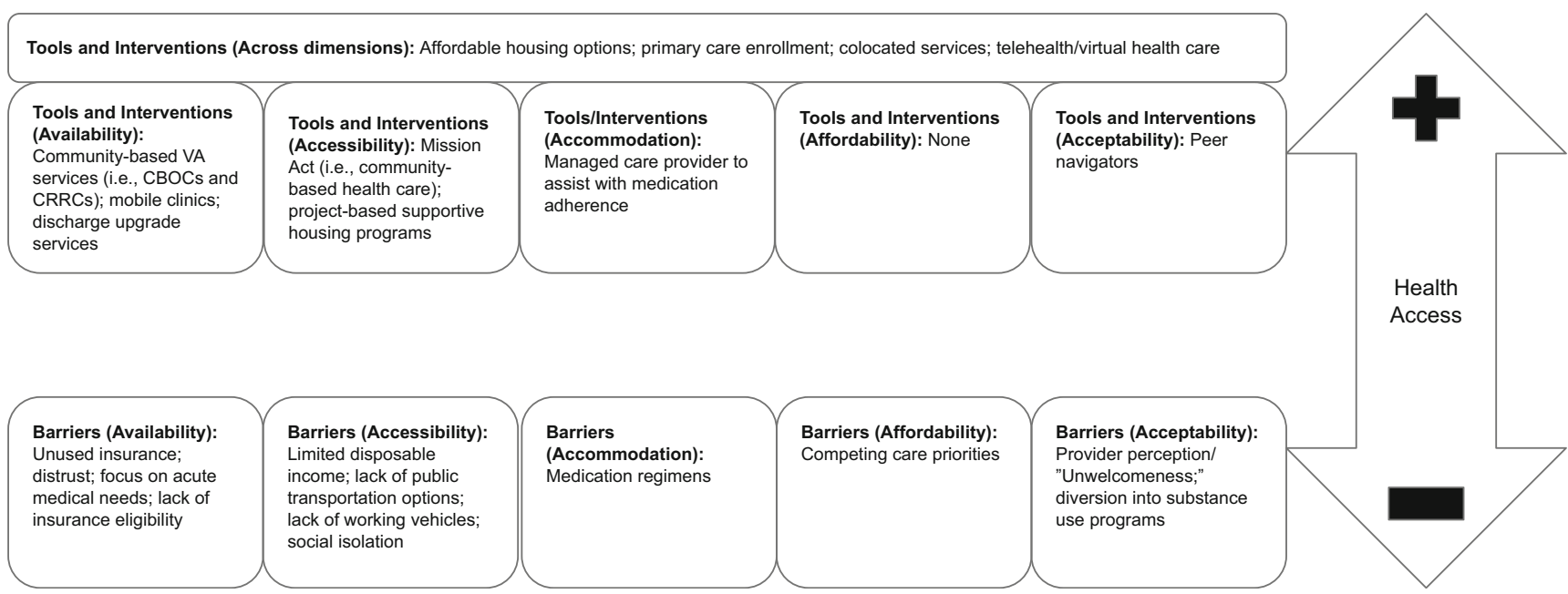

Fig. 1 Barriers and tools by dimension and across dimensions

services, their pattern of health service utilization implies that specific health services (e.g., preventive or specialty care) may not always be available. This is especially the case at VAMCs without H-PACTs to integrate homeless and health services. Availability hurdles exist even in the era of the VCP/Mission Act which was designed to mend gaps in access. Geared toward housed veterans, many VA services may not adequately reach the most underserved veterans.

Availability tools target these barriers: local community providers are particularly well suited to address Availability barriers with tools like mobile clinics and discharge upgrade services. To make better use of the VCP, local VAMC, CBOC, and CRRC staff can identify how homeless veterans in their service networks are accessing services outside of the VA. Community-based organizations can help identify active temporary addresses for veterans to receive VCP information. These adjustments can reach homeless veterans who do not have a usual source of care, who access available health services that do not match their medical needs, who are ineligible for VHA care, and who do not register for the health care for which they are eligible - including VA health care.

The Accessibility, Accommodation, and Affordability studies, on the other hand, present fewer interventions to target significant barriers. Among homeless veterans, the Accessibility dimension magnifies the role of transportation, social isolation, and geographic distance. A veteran experiencing homelessness may have fewer social reinforcements from family and friends regarding their health management, and they may feel helpless or overwhelmed regarding health decisions. As noted above, medication adherence may be the largest Accommodation barrier to health access among homeless veterans. Traveling to and attending medical appointments may prove too time- or resource-intensive, and therefore, a veteran may miss or never schedule appointments.
In these cases, the interventions identified in this review should be expanded, and additional measures can and should be taken to fully address barriers. The current VCP does not account for the burden homeless veterans face traveling shorter distances for medical care while relying on public transportation. Therefore, legislative or regulatory changes to the VCP regarding allowable transportation costs could improve access under this dimension.

To improve medication adherence, community-based managed care providers can offer basic medical services and medication management on site, so the veteran can engage with medical care on their own time. However, medical providers within the VA system can also play a more significant role in addressing this barrier: when medical providers are aware of a veteran's housing status, they can have a frank conversation about how best to manage needed medication and possible side effects.

The Homelessness Screening Clinical Reminder (HSCR) can be a useful tool for gaining information about a veteran's housing status. However, on its own, it is insufficient to connect veterans to health care. In one study, one-third of veterans who screened positive were not connected to triage services; the next step after screening must include triage and referral [114]. When a veteran screens positive for homelessness or risk using the clinical reminder, they can quickly be connected to triage services through homeless programs. This triage process is particularly important for homeless veterans over 45 , who are less likely than their younger peers to connect to services after screening [115], also lowering rates of follow-up for those with service connections. These tools should supplement - not replace - a compassionate conversation with the veteran about the best methods for engaging with needed medications. 
To improve Affordability, providers should aim to minimize the cost of receiving care in terms of time and effort. Many community providers can help meet Affordability gaps through the provision of their regular services. Some community agencies like GPD programs and Supportive Services For Veteran Families (SSVF) programs can help meet pressing unmet needs so health care rises higher on the list of priorities. Several Veteran Service Organizations (VSOs) offer transportation to and from medical appointments to decrease the time demand required by transportation itself. Health care providers do not need to know every resource in every community their VAMC serves, but they can develop a few contacts in the community who can serve as a lifeline for veterans in need who are consistently unable to afford attending medical appointments.

Addressing the Acceptability barrier of provider bias (or even the perception of provider bias) is a uniquely complicated process. The first step is to foster awareness within service agencies to recognize and identify implicit biases as it applies to their homeless clients, especially African American homeless veterans. At an organizational level, VA programs can utilize the VHA's Health Equity Action Plan's organizational assessment of health equity to identify implicit biases in their system of care. Integration of community member perspectives can also combat biases by ensuring the community's language and priorities are represented in health service materials and services.

This review has several limitations. This framework provides a means to organize and understand the key issues impeding access and identifying levers for improvement and yet is limited in that it relies on existing research identified through this review. There continues to be a paucity of research on health care access and health care disparities among homeless veterans, in particular among African American veterans. Where gaps in recent research exist, we must either rely on dated research or marginally comparable nonveteran studies. It is possible that homeless veterans interacting with the health service system may actually access health services in significantly different ways than we were able to identify here. Earlier attempts to apply health access models to vulnerable populations found that relative components of the conceptual model took on varied weight, so we can expect the weight of dimensions to shift as this topic is studied further.

\section{Data Availability Not applicable}

Code Availability Not applicable

\section{Declarations}

Ethics Approval This study did not require IRB approval.

$$
\text { Consent to Participate Not applicable }
$$

Consent for Publication All authors provided consent for publication.

Conflict of Interest The views expressed in this manuscript are those of the authors and do not reflect the official policy of the Uniformed Services University, Department of Army, Navy, Air Force, Department of Defense, or U.S. Government. The identification of specific products, scientific instrumentation, or organizations is considered an integral part of the scientific endeavor and does not constitute endorsement or implied endorsement on the part of the author, DoD, or any component agency. Additionally, the authors have no conflicts of interest to report.

\section{References}

1. Henry M, Mahathey A, Morrill T, et al. The 2018 Annual Homeless Assessment Report (AHAR) to Congress: part one. Washington, DC: The U.S. Department of Housing and Urban Development's Office of Community Development and Planning. 2018

2. Henry M, Bishop K, de Sousa T, et al. The 2017 Annual Homeless Assessment Report (AHAR) to Congress: part two. Washington, DC: The U.S. Department of Housing and Urban Development's Office of Community Development and Planning. 2018

3. Henry M, Watt R, Mahathey A, et al. The 2019 Annual Homeless Assessment Report (AHAR) to Congress: part one. Washington, DC: The U.S. Department of Housing and Urban Development's Office of Community Development and Planning. 2020

4. Gordon AJ, Haas GL, Luther JF, Hilton MT, Goldstein G. Personal, medical, and healthcare utilization among homeless veterans served by metropolitan and nonmetropolitan veteran facilities. Psychol Serv. 2010;7(2):65-74. https://doi.org/10.1037/ a0018479.

5. Wray NP, Weiss TW, Christian CE, Menke T, Ashton CM, Hollingsworth JC. The health status of veterans using mobile clinics in rural areas. J Health Care Poor Underserved. 1999;10(3):338-48. https://doi.org/10.1353/hpu.2010.0527.

6. Fargo J, Metraux S, Byrne T, et al. Prevalence and risk of homelessness among US veterans. Prev Chronic Dis. 2012;9:E45.

7. Rosenheck R, Fontana A. A model of homelessness among male veterans of the Vietnam War generation. Am J Psychiatry. 1994;151(3):421-7. https://doi.org/10.1176/ajp.151.3.421.

8. Tsai J, Hoff RA, Harpaz-Rotem I. One-year incidence and predictors of homelessness among 300,000 U.S. veterans seen in specialty mental health care. Psychol Serv. 2017;14(2):203-7. https:// doi.org/10.1037/ser0000083.

9. Edens EL, Kasprow W, Tsai J, Rosenheck RA. Association of substance use and VA service-connected disability benefits with risk of homelessness among veterans. Am J Addict. 2011;20(5): 412-9. https://doi.org/10.1111/j.1521-0391.2011.00166.x.

10. Barrow SM, Herman DB, Córdova P, Struening EL. Mortality among homeless shelter residents in New York City. Am J Public Health. 1999;89(4):529-34. https://doi.org/10.2105/ajph. 89.4.529.

11. Hibbs JR, Benner L, Klugman L, Spencer R, Macchia I, Mellinger AK, et al. Mortality in a cohort of homeless adults in Philadelphia. N Engl J Med. 1994;331(5):304-9. https://doi.org/10.1056/ NEJM199408043310506.

12. Schinka JA, Bossarte RM, Curtiss G, Lapcevic WA, Casey RJ. Increased mortality among older veterans admitted to VA homelessness programs. Psychiatr Serv. 2016;67(4):465-8. https://doi. org/10.1176/appi.ps.201500095.

13. D'Amore J, Hung O, Chiang W, Goldfrank L. The epidemiology of the homeless population and its impact on an urban emergency 
department. Acad Emerg Med. 2001;8(11):1051-5. https://doi. org/10.1111/j.1553-2712.2001.tb01114.x.

14. Harris T, Winetrobe H, Rhoades H, Castro CA, Wenzel S. Moving beyond housing: service implications for veterans entering permanent supportive housing. Clin Soc Work J. 2018;46(2): 130-44. https://doi.org/10.1007/s10615-018-0648-7.

15. Morrison DS. Homelessness as an independent risk factor for mortality: results from a retrospective cohort study. Int $\mathrm{J}$ Epidemiol. 2009;38(3):877-83. https://doi.org/10.1093/ije/ dyp160.

16. O'Toole TP, Bourgault C, Johnson EE, et al. New to care: demands on a health system when homeless veterans are enrolled in a medical home model. Am J Public Health. 2013;103(Suppl 2):S374-9. https://doi.org/10.2105/AJPH.2013.301632.

17. Eibner C, Krull H, Brown KM, et al. Current and projected characteristics and unique health care needs of the patient population served by the Department of Veterans Affairs. Rand Health Q. 2016;5(4):13 Published 2016 May 9.

18. O'Toole TP, Gibbon JL, Hanusa BH, Fine MJ. Utilization of health care services among subgroups of urban homeless and housed poor. J Health Polit Policy Law. 1999;24(1):91-114. https://doi.org/10.1215/03616878-24-1-91.

19. Gabrielian S, Yuan AH, Andersen RM, Rubenstein LV, Gelberg L. VA health service utilization for homeless and low-income veterans: a spotlight on the VA Supportive Housing (VASH) program in greater Los Angeles. Med Care. 2014;52(5):454-61. https://doi.org/10.1097/MLR.0000000000000112.

20. Schinka JA, Leventhal KC, Lapcevic WA, Casey R. Mortality and cause of death in younger homeless veterans. Public Health Rep. 2018;133(2):177-81. https://doi.org/10.1177/0033354 918755709

21. Brown LM, Barnett SD, Frahm KA, Schinka JA, Schonfeld L, Casey RJ. Health risk factors and differences in outcomes between younger and older veterans using VA transitional housing. Psychiatr Serv. 2015;66(1):33-40. https://doi.org/10.1176/appi. ps.201400022.

22. Tsai J. Introduction and history of veteran homelessness In: Tsai J, ed. Homelessness among US veterans: critical perspectives, 2019.

23. Baggett TP, O'Connell JJ, Singer DE, Rigotti NA. The unmet health care needs of homeless adults: a national study. Am J Public Health. 2010;100(7):1326-33. https://doi.org/10.2105/ AJPH.2009.180109.

24. Institute of Medicine Committee on Monitoring Access to Personal Health Care Services. Access to health care in America. Millman M, ed. Washington, DC, National Academies Press, 1993

25. Karikari-Martin P. Use of healthcare access models to inform the patient protection and affordable care act. Policy, politics \& nursing practice. 2010;11(4):286-93. https://doi.org/10.1177/ 1527154410393741.

26. Gelberg L, Andersen RM, Leake BD. The behavioral model for vulnerable populations: application to medical care use and outcomes for homeless people. Health Serv Res. 2000;34(6):1273302.

27. Brown ER, Davidson PL, Yu H, Wyn R, Andersen RM, Becerra $\mathrm{L}$, et al. Effects of community factors on access to ambulatory care for lower-income adults in large urban communities. Inquiry. 2004;41(1):39-56. https://doi.org/10.5034/inquiryjrnl_41.1.39.

28. King RK, Green AR, Tan-McGrory A, Donahue EJ, KimbroughSugick J, Betancourt JR. A plan for action: key perspectives from the racial/ethnic disparities strategy forum. Milbank Q. 2008;86(2):241-72. https://doi.org/10.1111/j.1468-0009.2008. 00521.x.

29. Andersen R. A behavioral model of families' use of health services. Center for Health Administration Studies Research Series. Chicago, IL: University of Chicago Press 1968
30. Austin EL, Andersen R, Gelberg L. Ethnic differences in the correlates of mental distress among homeless women. Womens Health Issues. 2008;18(1):26-34. https://doi.org/10.1016/j.whi. 2007.08.005

31. Gelberg L, Browner CH, Lejano E, Arangua L. Access to women's health care: a qualitative study of barriers perceived by homeless women. Women Health. 2004;40(2):87-100. https:// doi.org/10.1300/J013v40n02_06.

32. Gelberg L, Gallagher TC, Andersen RM, Koegel P. Competing priorities as a barrier to medical care among homeless adults in Los Angeles. Am J Public Health. 1997;87(2):217-20. https://doi. org/10.2105/ajph.87.2.217.

33. Kushel MB, Gupta R, Gee L, Haas JS. Housing instability and food insecurity as barriers to health care among low-income Americans. J Gen Intern Med. 2006;21(1):71-7. https://doi.org/ 10.1111/j.1525-1497.2005.00278.x.

34. Stein JA, Andersen R, Gelberg L. Applying the Gelberg-Andersen behavioral model for vulnerable populations to health services utilization in homeless women. J Health Psychol. 2007;12(5): 791-804. https://doi.org/10.1177/1359105307080612.

35. Penchansky R, Thomas JW. The concept of access: definition and relationship to consumer satisfaction. Med Care. 1981;19(2):12740. https://doi.org/10.1097/00005650-198102000-00001.

36. Stein J, Andersen R, Koegel P, Gelberg L. Predicting health services utilization among homeless adults: a prospective analysis. $\mathrm{J}$ Health Care Poor Underserved. 2000;11:212-30. https://doi.org/ 10.1353/hpu.2010.0675.

37. Levesque JF, Harris MF, Russell G. Patient-centred access to health care: conceptualising access at the interface of health systems and populations. Int J Equity Health. 2013;12:18. Published 2013 Mar 11. https://doi.org/10.1186/1475-9276-12-18.

38. Ricketts TC, Goldsmith LJ. Access in health services research: the battle of the frameworks. Nurs Outlook. 2005;53(6):274-80. https://doi.org/10.1016/j.outlook.2005.06.007.

39. Thomas JW, Penchansky R. Relating satisfaction with access to utilization of services. Med Care. 1984;22(6):553-68. https://doi. org/10.1097/00005650-198406000-00006.

40. Penchansky R. The concept of access, a definition. Hyattsville, MD: Bureau of Health Planning Resources Development, Department of Health, Education and Welfare, 1997.

41. Congressional Research Service (2016a). Health care for veterans: answers to frequently asked questions (CRS R42747). Retrieved from Congressional Research Service website: https://crsreports. congress.gov/product/pdf/R/R42747.

42. Congressional Research Service (2018). The Veterans Choice Program (VCP): program implementation (CRS R44562). Retrieved from Congressional Research Service website: https:// crsreports.congress.gov/product/pdf/R/R44562.

43. Congressional Research Service (2016b). Telehealth and telemedicine: description and issues (CRS R44437). Retrieved from Congressional Research Service website: https://crsreports. congress.gov/product/pdf/R/R44437.

44. O'Toole TP, Conde-Martel A, Gibbon JL, Hanusa BH, Fine MJ. Health care of homeless veterans. J Gen Intern Med. 2003;18(11): 929-33. https://doi.org/10.1046/j.1525-1497.2003.21209.x.

45. Desai MM, Rosenheck RA, Kasprow WJ. Determinants of receipt of ambulatory medical care in a national sample of mentally ill homeless veterans. Med Care. 2003;41(2):275-87. https://doi.org/ 10.1097/01.MLR.0000044907.31129.0A.

46. Armstrong K, Rose A, Peters N, Long JA, McMurphy S, Shea JA. Distrust of the health care system and self-reported health in the United States. J Gen Intern Med. 2006;21(4):292-7. https://doi. org/10.1111/j.1525-1497.2006.00396.x.

47. Cheney AM, Koenig CJ, Miller CJ, et al. Veteran-centered barriers to VA mental healthcare services use. BMC Health Serv Res. 
2018;18(1):591. Published 2018 Jul 31. https://doi.org/10.1186/ s12913-018-3346-9.

48. Padgett DK, Struening EL, Andrews H, Pittman J. Predictors of emergency room use by homeless adults in New York City: the influence of predisposing, enabling and need factors. Soc Sci Med. 1995;41(4):547-56. https://doi.org/10.1016/0277-9536(94) 00364-y.

49. Feigal J, Park B, Bramante C, Nordgaard C, Menk J, Song J. Homelessness and discharge delays from an urban safety net hospital. Public Health. 2014;128(11):1033-5. https://doi.org/10. 1016/j.puhe.2014.06.001.

50. Wenzel SL, Bakhtiar L, Caskey NH, et al. Homeless veterans' utilization of medical, psychiatric, and substance abuse services. Med Care. 1995;33(11):1132-44. https://doi.org/10.1097/ 00005650-199511000-00006.

51. Gilmer TP, Manning WG, Ettner SL. A cost analysis of San Diego County's REACH program for homeless persons. Psychiatr Serv. 2009;60(4):445-50. https://doi.org/10.1176/appi.ps.60.4.445.

52. Montgomery AE, Cusack M, Szymkowiak D, Fargo J, O'Toole T. Factors contributing to eviction from permanent supportive housing: lessons from HUD-VASH. Eval Program Plann. 2017;61:5563. https://doi.org/10.1016/j.evalprogplan.2016.11.014.

53. Congressional Research Service (2016c). Who is a "veteran"?basic eligibility for veterans' benefits (CRS R42324). Retrieved from Congressional Research Service website: https:// crsreports.congress.gov/product/pdf/R/R42324.

54. Gamache G, Rosenheck R, Tessler R. Military discharge status of homeless veterans with mental illness. Mil Med. 2000;165(11): 803-8.

55. Government Accountability Office. (2000). Homelessness: barriers to using mainstream programs. (GAO Publication No. 00184). Washington, D.C.: U.S. Government Printing Office.

56. Weissman EM, Covell NH, Kushner M, Irwin J, Essock SM. Implementing peer-assisted case management to help homeless veterans with mental illness transition to independent housing. Community Ment Health J. 2005;41(3):267-76. https://doi.org/ 10.1007/s10597-005-5001-2.

57. Cretzmeyer M, Moeckli J, Liu WM. Barriers and facilitators to Veterans Administration collaboration with community providers: the Lodge Project for homeless veterans. Soc Work Health Care. 2014;53(8):698-713. https://doi.org/10.1080/00981389.2014. 930371.

58. Surís A, Holliday R, Hooshyar D, et al. Development and implementation of a homeless mobile medical/mental veteran intervention. Fed Pract. 2017;34(9):18-25.

59. Blue-Howells J. Community Homelessness Assessment, Local Education and Networking Groups (CHALENG). Washington, DC: The U.S Department of Veterans Affairs Office of Public Affairs and Media Relations. 2019

60. Tsai J, Rosenheck RA. Characteristics and health needs of veterans with other-than-honorable discharges: expanding eligibility in the Veterans Health Administration. Mil Med. 2018;183(5-6): e153-7. https://doi.org/10.1093/milmed/usx110.

61. Fortney JC, Booth BM, Blow FC, Bunn JY. The effects of travel barriers and age on the utilization of alcoholism treatment aftercare. Am J Drug Alcohol Abuse. 1995;21(3):391-406. https://doi. org/10.3109/00952999509002705.

62. Priester MA, Browne T, Iachini A, Clone S, DeHart D, Seay KD. Treatment access barriers and disparities among individuals with co-occurring mental health and substance use disorders: an integrative literature review. J Subst Abus Treat. 2016;61:47-59. https://doi.org/10.1016/j.jsat.2015.09.006.

63. Syed ST, Gerber BS, Sharp LK. Traveling towards disease: transportation barriers to health care access. J Community Health. 2013;38(5):976-93. https://doi.org/10.1007/s10900-013-9681-1.
64. Henwood BF, Cabassa LJ, Craig CM, Padgett DK. Permanent supportive housing: addressing homelessness and health disparities. Am J Public Health. 2013;103 Suppl 2(Suppl 2):S188-92. https://doi.org/10.2105/AJPH.2013.301490.

65. Metraux S, Cusack M, Byrne TH, Hunt-Johnson N, True G. Pathways into homelessness among post-9/11-era veterans. Psychol Serv. 2017;14(2):229-37. https://doi.org/10.1037/ ser0000136.

66. Chinchilla M, Gabrielian S, Glasmeier A, Green MF. Exploring community integration among formerly homeless veterans in project-based versus tenant-based supportive housing. Community Ment Health J. 2020;56(2):303-12. https://doi.org/ 10.1007/s10597-019-00473-x.

67. Kinchen K, Wright JD. Hypertension management in health care for the homeless clinics: results from a survey. Am J Public Health. 1991;81(9):1163-5. https://doi.org/10.2105/ajph.81.9. 1163.

68. Kushel MB, Vittinghoff E, Haas JS. Factors associated with the health care utilization of homeless persons. JAMA. 2001;285(2): 200-6. https://doi.org/10.1001/jama.285.2.200.

69. Weber J, Lee RC, Martsolf D. Pursuing the mission: how homeless veterans manage chronic disease. Glob Qual Nurs Res. 2018;5:2333393618792093. Published 2018 Aug 9. https://doi. org $/ 10.1177 / 2333393618792093$.

70. Gundlapalli A, Nelson R, Haroldsen C, Carter ME, LaFleur J. Correlates of initiation of treatment for chronic hepatitis $\mathrm{C}$ infection in United States Veterans, 2004-2009. PLoS One. 2015;10(8):1-16.

71. VHA Homeless Program Office (2013). GPD medication storage FAQs. Washington, D.C.: U.S. Government Printing Office.

72. Zucchero T, McDannold S, McInnes DK. 'Walking in a maze': community providers' difficulties coordinating health care for homeless patients. BMC Health Serv Res. 2016;16(480):1-9.

73. Zur J, Mojtabai R, Li S. The cost savings of expanding Medicaid eligibility to include currently uninsured homeless adults with substance use disorders. J Behav Health Serv Res. 2014;41(2): 110-24. https://doi.org/10.1007/s11414-013-9366-7.

74. Shulman C, Hudson BF, Low J, Hewett N, Daley J, Kennedy P, et al. End-of-life care for homeless people: a qualitative analysis exploring the challenges to access and provision of palliative care. Palliat Med. 2018;32(1):36-45. https://doi.org/10.1177/ 0269216317717101

75. Wen CK, Hudak PL, Hwang SW. Homeless people's perceptions of welcomeness and unwelcomeness in healthcare encounters. J Gen Intern Med. 2007;22(7):1011-7. https://doi.org/10.1007/ s11606-007-0183-7.

76. Jones AL, Hausmann LRM, Haas GL, Mor MK, Cashy JP, Schaefer JH, et al. A national evaluation of homeless and nonhomeless veterans' experiences with primary care. Psychol Serv. 2017;14(2):174-83. https://doi.org/10.1037/ser0000116.

77. O'Toole TP, Johnson EE, Redihan S, Borgia M, Rose J. Needing primary care but not getting it: the role of trust, stigma and organizational obstacles reported by homeless veterans. J Health Care Poor Underserved. 2015;26(3):1019-31. https://doi.org/10.1353/ hpu.2015.0077.

78. Hamilton AB, Poza I, Hines V, Washington DL. Barriers to psychosocial services among homeless women veterans. J Soc Work Pract Addict. 2012;12(1):52-68. https://doi.org/10.1080/ 1533256X.2012.647584.

79. Gabrielian S, Chen JC, Minhaj BP, Manchanda R, Altman L, Koosis E, et al. Feasibility and acceptability of a colocated homeless-tailored primary care clinic and emergency department. J Prim Care Community Health. 2017;8(4):338-44. https://doi. org/10.1177/2150131917699751.

80. Gilmer C, Buccieri K. Homeless patients associate clinician bias with suboptimal care for mental illness, addictions, and chronic 
pain. J Prim Care Community Health. 2020;11: 2150132720910289. https://doi.org/10.1177/215013272 0910289.

81. Rae BE, Rees $\mathrm{S}$. The perceptions of homeless people regarding their healthcare needs and experiences of receiving health care. J Adv Nurs. 2015;71(9):2096-107. https://doi.org/10.1111/jan. 12675.

82. Semeah LM, Campbell CL, Cowper DC, Peet AC. Serving our homeless veterans: patient perpetrated violence as a barrier to health care access. J Public and Nonprofit Affairs. 2017;3(2): 223-34.

83. Doran KM, Shumway M, Hoff RA, Blackstock OJ, Dilworth SE, Riley ED. Correlates of hospital use in homeless and unstably housed women: the role of physical health and pain. Womens Health Issues. 2014;24(5):535-41. https://doi.org/10.1016/j.whi. 2014.06.003.

84. Fischer PJ, Shapiro S, Breakey WR, Anthony JC, Kramer M. Mental health and social characteristics of the homeless: a survey of mission users. Am J Public Health. 1986;76(5):519-24. https:// doi.org/10.2105/ajph.76.5.519.

85. Hill JO, Galloway JM, Goley A, Marrero DG, Minners R, Montgomery B, et al. Scientific statement: socioecological determinants of prediabetes and type 2 diabetes. Diabetes Care. 2013;36(8):2430-9. https://doi.org/10.2337/dc13-1161.

86. Resnik L, Ekerholm S, Johnson EE, Ellison ML, O'Toole TP. Which homeless veterans benefit from a peer mentor and how? J Clin Psychol. 2017;73(9):1027-47. https://doi.org/10.1002/jclp. 22407.

87. Corrigan PW, Kraus DJ, Pickett SA, Schmidt A, Stellon E, Hantke $\mathrm{E}$, et al. Using peer navigators to address the integrated health care needs of homeless African Americans with serious mental illness. Psychiatr Serv. 2017;68(3):264-70. https://doi.org/10.1176/appi. ps.201600134.

88. Corrigan P, Pickett S, Kraus D, Burks R, Schmidt A. Communitybased participatory research examining the health care needs of African Americans who are homeless with mental illness. J Health Care Poor Underserved. 2015;26(1):119-33. https://doi.org/10. 1353/hpu.2015.0018

89. Van Voorhees EE, Resnik L, Johnson E, O'Toole T. Posttraumatic stress disorder and interpersonal process in homeless veterans participating in a peer mentoring intervention: associations with program benefit. Psychol Serv. 2019;16(3):463-74. https://doi.org/ 10.1037/ser0000231.

90. Molinari VA, Brown LM, Frahm KA, Schinka JA, Casey R. Perceptions of homelessness in older homeless veterans, VA homeless program staff liaisons, and housing intervention providers. J Health Care Poor Underserved. 2013;24(2):487-98. https://doi.org/10.1353/hpu.2013.0089.

91. Montgomery AE, Hill L, Kane V, Culhane D. Housing chronically homeless veterans: evaluating the efficacy of a housing first approach to HUD-VASH. J Community Psych. 2013;41(4):505-14.

92. Jaworsky D, Gadermann A, Duhoux A, Naismith TE, Norena M, To MJ, et al. Residential stability reduces unmet health care needs and emergency department utilization among a cohort of homeless and vulnerably housed persons in Canada. J Urban Health. 2016;93(4):666-81. https://doi.org/10.1007/s11524-016-0065-6.

93. Nunez E, Gibson G, Jones JA, Schinka JA. Evaluating the impact of dental care on housing intervention program outcomes among homeless veterans. Am J Public Health. 2013;103 Suppl 2(Suppl 2):S368-73. https://doi.org/10.2105/AJPH.2012.301064.

94. Culhane DP, Metraux S, Hadley T. Public service reductions associated with placement of homeless persons with severe mental illness in supportive housing. Hous Policy Debate. 2002;13(1): $107-63$.
95. Fischer W. Research shows housing vouchers reduce hardship and provide platform for long-term gains among children. Center on Budget and Policy Priorities. 2015

96. Tsai J, Kasprow WJ, Rosenheck RA. Latent homeless risk profiles of a national sample of homeless veterans and their relation to program referral and admission patterns. Am J Public Health. 2013;103 Suppl 2(Suppl 2):S239-47. https://doi.org/10.2105/ AJPH.2013.301322.

97. Johnson EE, Borgia M, Rose J, O'Toole TP. No wrong door: can clinical care facilitate veteran engagement in housing services? Psychol Serv. 2017;14(2):167-73. https://doi.org/10.1037/ ser0000124.

98. O'Toole TP, Buckel L, Bourgault C, Blumen J, Redihan SG, Jiang $\mathrm{L}$, et al. Applying the chronic care model to homeless veterans: effect of a population approach to primary care on utilization and clinical outcomes. Am J Public Health. 2010;100(12):2493-9. https://doi.org/10.2105/AJPH.2009.179416.

99. Montgomery AE, Cusack M, Blonigen DM, Gabrielian S, Marsh L, Fargo J. Factors associated with veterans' access to permanent supportive housing. Psychiatr Serv. 2016;67(8):870-7. https://doi. org/10.1176/appi.ps.201500248.

100. Dobbins SK, Cruz M, Shah S, Abt L, Moore J, Bamberger J. Nurses in supportive housing are associated with decreased health care utilization and improved HIV biomarkers in formerly homeless adults. J Assoc Nurses AIDS Care. 2016;27(4):444-54. https://doi.org/10.1016/j.jana.2016.01.002.

101. Chinman M, Hannah G, McCarthy S. Lessons learned from a quality improvement intervention with homeless veteran services. J Health Care Poor Underserved. 2012;23(3 Suppl):210-24. https://doi.org/10.1353/hpu.2012.0125.

102. Simmons MM, Gabrielian S, Byrne T, et al. A hybrid III stepped wedge cluster randomized trial testing an implementation strategy to facilitate the use of an evidence-based practice in VA Homeless Primary Care Treatment Programs. Implement Sci. 2017;12(1):46. Published 2017 Apr 4. https://doi.org/10.1186/s13012-017-0563-2.

103. Simmons MM, Fincke BG, Drainoni ML, et al. A two-state comparative implementation of peer-support intervention to link veterans to health-related services after incarceration: a study protocol. BMC Health Serv Res. 2017;17(1):647. Published 2017 Sep 12. https://doi.org/10.1186/s12913-017-2572-x.

104. Smelson DA, Kline A, Kuhn J, Rodrigues S, O'Connor K, Fisher $\mathrm{W}$, et al. A wraparound treatment engagement intervention for homeless veterans with co-occurring disorders. Psychol Serv. 2013;10(2):161-7. https://doi.org/10.1037/a0030948.

105. Smelson DA, Chinman M, Hannah G, Byrne T, McCarthy S. An evidence-based co-occurring disorder intervention in VA homeless programs: outcomes from a hybrid III trial. BMC Health Serv Res. 2018;18(1):332. Published 2018 May 5. https://doi.org/10. 1186/s12913-018-3123-9.

106. O'Toole TP, Johnson EE, Aiello R, Kane V. Tailoring care to vulnerable populations by incorporating social determinants of health: the Veterans Health Administration's "Homeless Patient Aligned Care Team" program. Prev Chronic Dis. 2016;13(44):1-12.

107. Pauly JB, Moore TA, Shishko I. Integrating a mental health clinical pharmacy specialist into the Homeless Patient Aligned Care Teams. Ment Health Clin. 2018;8(4):169-74. Published 2018 Jun 29. https://doi.org/10.9740/mhc.2018.07.169.

108. McInnes DK, Sawh L, Petrakis BA, et al. The potential for healthrelated uses of mobile phones and internet with homeless veterans: results from a multisite survey. Telemed J E Health. 2014;20(9): 801-9. https://doi.org/10.1089/tmj.2013.0329.

109. Gabrielian S, Yuan A, Andersen RM, McGuire J, Rubenstein L, Sapir N, et al. Chronic disease management for recently homeless veterans: a clinical practice improvement program to apply home telehealth technology to a vulnerable population. Med Care. 
2013;51(3 Suppl 1):S44-51. https://doi.org/10.1097/MLR. 0b013e31827808f6.

110. Sen, M. \& Wasow, O. (2016). Race as a bundle of sticks: designs that estimate effects of seemingly immutable characteristics Annual Review of Political Science, 19, 499-522

111. Ioannidis JP, Powe NR, Yancy C. Recalibrating the use of race in medical research. JAMA. 2021;325(7):623-4. https://doi.org/10. 1001/jama.2021.0003.

112. O'Toole TP, Johnson EE, Borgia ML, Rose J. Tailoring outreach efforts to increase primary care use among homeless veterans: results of a randomized controlled trial. J Gen Intern Med. 2015;30(7):886-98. https://doi.org/10.1007/s11606-015-3193-x.

113. Cusack M, Montgomery AE, Hunt-Johnson N, Dichter M, True G. Making connections: understanding how screening, triage, and referral processes can promote veteran housing stability. Soc Work Public Health. 2019;34(6):483-91. https://doi.org/10. 1080/19371918.2019.1629143.
114. Lee C. "Race" and "ethnicity" in biomedical research: how do scientists construct and explain differences in health? Soc Sci Med. 2009;68(6):1183-90. https://doi.org/10.1016/j.socscimed. 2008.12.036.

115. Montgomery AE, Dichter ME, Thomasson AM, Roberts CB. Services receipt following veteran outpatients' positive screen for homelessness. Am J Prev Med. 2016;50(3):336-43. https://doi. org/10.1016/j.amepre.2015.06.035.

Publisher's Note Springer Nature remains neutral with regard to jurisdictional claims in published maps and institutional affiliations.

Springer Nature or its licensor holds exclusive rights to this article under a publishing agreement with the author(s) or other rightsholder(s); author self-archiving of the accepted manuscript version of this article is solely governed by the terms of such publishing agreement and applicable law. 